\title{
PRELIMINARY REVISION OF THE EVIDENCE RE- LATING TO AURIFEROUS GRAVEL MAN IN CALIFORNIA
}

\author{
BY WILLIAM H. HOLMES
}

\author{
SECOND PAPER
}

\section{INTRODUCTION}

The main features of the problem of Auriferous Gravel man in California stand out in bold relief. On the one hand the evidence is interpreted as establishing the existence of a Tertiary man of high type physically and mentally, equal or superior to the Indian tribes of the region today, and occupying a culture plane corresponding to the polished stone age of Europe. It is assumed that this remotely ancient man continued to live and thrive, without perceptible advance or retrogression, while nature passed through a thousand centuries of revolution; or that, as an alternative proposition, if the Tertiary race did not persist but disappeared along with the other mammalian fauna of the time, a new race sprang up, duplicating the physical characters and culture of a former geologic period. There are those high in the councils of anthropologic and geologic science who profess to see no reason for rejecting these bold and extraordinary propositions. On the other hand, there are those who hold that the facts adduced do not warrant either of these conclusions, who see in the whole body of observations and assumptions only a mass of errors and misinterpretations. Thus for a number of years the opposing views have stood without apparent change, the proofs, though strong, not being sufficiently decisive to carry full conviction with regard to a proposition of such exceptional magni- 
tude. It is probable that without positive reinforcement the evidence would gradually lose its hold and disappear; but science cannot afford to await this tedious process of selection, and some attempt to hasten a decision is demanded. If new evidence cannot be found, renewed discussion will at least develop the full strength or weakness of the old, and it is especially desirable to take this matter up while some of the pioneers of the Sierra are still with us.

It has been shown in a preceding paper that much of the testimony furnished by Whitney is not well considered, and that there is excellent reason for questioning or rejecting most of the observations placed on record regarding the deep finds. The mines of the more northern counties, already referred to in some detail, seem to have furnished nothing that can be relied upon to prove anything more than the presence of the Digger tribes or their immediate predecessors in the region, and it remains now to look critically into the evidence furnished by the vast diggings of the south, and especially in the great valleys of the Tuolumne and the Stanislaus.

TABLE MOUNTAIN REGION

The region of Table mountain in Tuolumne and Calaveras counties has yielded a large part of the testimony most relied on to establish the theory of an Auriferous Gravel man. Here finds have been reported in bewildering numbers, the objects coming from many sources, often apparently wholly independent of one another. During my visit to this region I sought to get back as near as possible to original sources of information, to see the people having personal knowledge of the finds, and to acquire a correct notion of the aboriginal occupancy before, during, and since the great period of mining activity.

Indian Implements in Mines.-Accompanied by Prof. W J McGee, I journeyed from Jamestown, the railway terminus, situated under the eastern escarpment of Table mountain, to 
Sonora, Sawmill Flat, Yankee Hill, Columbia, Springfield, and Shaw's Flat. I crossed over and passed around Table mountain, visiting Rawhide and Tuttletown; and traversing the great gorge of the Stanislaus, spent several days in the vicinity of Murphy's, Altaville, and Angels Camp. These places were all centers of great activity in the early days of gold mining, as amply attested by vast excavations covering many square miles of territory; and I was told by those who had seen it that the Indians flocked in from the surrounding mountains to such an extent that it was not unusual to see the lodges of a thousand Diggers gathered about a single camp; and the hills and valleys still bear ample evidence of their presence. Numberless pits and trenches were then gaping to receive the scattered utensils of these people, whose village sites one after another were undermined and destroyed, and collectors reaped a goodly harvest of supposed ancient relics from the mines. The Snell collection, referred to by Whitney and culled from by Voy, was gathered from this locality and consisted of the usual stone implements and utensils of the Indian tribes, as well as of several forms not in common use today and thought by some to especially represent the ancient time. A remnant of this collection is now owned by $\mathrm{Mr}$ J. W. Pownall of Columbia, and will probably pass eventually into the keeping of the University of California. Three specimens were obtained for the National Museum.

As indicated in the preceding paragraph, a thorough knowledge of the aboriginal occupancy is of vital importance in this discussion; but Whitney knew little of the native culture, as his remarks amply show, and he could not have separated objects that had fallen in or had been introduced by other means into the mines from like objects originally belonging in the gravelif such there were. Neither Whitney nor Voy, so far as I can learn, had any idea of the need and vital importance of such discrimination. Their lists of finds from the mines are hardly more than lists of Indian implements. 
Implements from Deep Tunnels.-But what is to be said of the finds reported from the deep shafts and tunnels that penetrate obliquely or horizontally beneath the lava-capped summits of Table mountain? (See figure 26.) Relics of the swarming Diggers could not fall in horizontally, and if these relics do not belong with the fossil animals and plants in the gravels of the ancient river channels, we are left to determine how they could have been introduced, or how deception was so successfully and generally practiced.

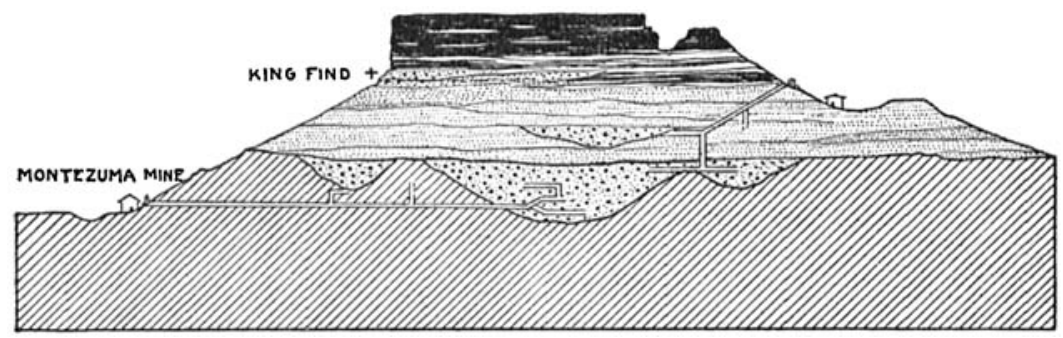

FIG. 26-Section of Table mountain showing mines penetrating to old river channels. The tunnels are not literally rendered, but are sketched in merely to show the methods of reaching the gold gravels.

The fact that the implements recovered from the deep horizontal diggings are, so far as I have encountered them, all identical in type with the prevailing recent forms, emphasizes the need of inquiring with the utmost care as to whether or not these implements could have been introduced while the mines were in operation. As already shown, the mountain Indians were in those days very numerous about the mining camps. The men were employed to a considerable extent in the mines, and it is entirely reasonable to suppose that their implements and utensils would at times be carried into the mines, perhaps to prepare or contain food, or perhaps merely as a natural proceeding with half-nomadic peoples habitually carrying their property about with them from want of a house in which to lock it up. That any kind of native implement should be carried into the tunnels, there to be lost or forgotten and covered up as the handling and rehandling of gravels went on, is not unnatural. 
That such should be afterward dug up with the reopening of passageways and the shifting of the tailings is to be expected, for the search for gold under these old lava beds was not a straightaway boring of the mountains, but a driving and redriving of tunnels in any direction that promised renewed finds of pay material. As a matter of course little attention was paid to the comings and goings of the humble helpers, and if miners came upon stray implements buried in the gravels it is quite natural that they should report them to the foremen or superintendents without seriously considering the question as to recent or ancient origin. Naturally little value was attached to such specimens, as the real significance of their occurrence in the old gravel was at most but dimly understood.

Again, let us not forget, it would be quite within the bounds of probability that some fun-loving miner should seek amusement by reporting objects found about the camp, to the superintendent or others, pretending that they came from beneath the mountain. There can be no doubt that practical joking of this character was prevalent in those days, and that implements of the classes involved in this discussion were known by the miners to excite unusual interest in religious as well as scientific quarters. There are thus two ways in which errors might have crept into the evidence-two ways either of which would lead to that repetition of like finds which is considered so significant by advocates of antiquity.

The Neale Finds. - The case cited in detail by Dr Becker may well illustrate what I have been saying, and this case, it should be noted, is a typical one and constitutes one of the strongest bits of testimony of its class on record. ${ }^{1} \mathrm{Mr} \mathrm{J}$. H. Neale was superintendent of the Montezuma mine, situated on the western slope of Table mountain, four or five miles southwest of the village of Jamestown. The gold-bearing gravels of the old river bed be-

${ }^{1}$ Geo. F. Becker, Antiquities from under Tuolumne Table mountain in California; Bull. Geol. Soc. of America, vol. II, p. 189. 
neath the mountain, covered by the claim, became exhausted and the mine was closed several years ago. Mr Neale now resides in the town of Sonora, five miles north of Jamestown. In 1877 , according to $\mathrm{Dr}$ Becker's account, $\mathrm{Mr}$ Neale discovered some mortars, pestles, and obsidian implements in the deepest part of the mine, beneath Table mountain and close to the bed-rock. These objects soon passed out of his hands, and one of the mortars with the accompanying pestle (see plate XXVIII) was given to $\mathrm{Dr}$ R. I. Bromley of Sonora. Ten years after the finding, these specimens came to the notice of Dr Becker, who, desiring to learn more of their origin, sought out $\mathrm{Mr}$ Neale, and obtained the statement to which affidavit was made, the circumstances being given in detail in Dr Becker's paper. The essential paragraphs of the document are as follows:

"At a distance of between $r, 400$ and 1,500 feet from the mouth of the tunnel, or of between 200 and 300 feet beyond the edge of the solid lava, $\mathrm{Mr}$ Neale saw several spear-heads, of some dark rock and nearly one foot in length. On exploring further, he himself found a small mortar three or four inches in diameter and of irregular shape. This was discovered within a foot or two of the spear-heads. He then found a large, well-formed pestle, now the property of $\mathrm{Dr} \mathrm{R}$. I. Bromley, and near by a large and very regular mortar, also at present the property of $\mathrm{Dr}$ Bromley.

"All of these relics were found the same afternoon, and were within a few feet of one another and close to the bed-rock, perhaps within one foot of it." (P. 192.)

I took the trouble to visit the mine, which was found closed and caved in about the mouth, and with a newly opened mine along side. The site is on a steep slope, falling away to the west from the base of the towering escarpment of the mountain (and apparently much more than 1500 feet from it), and is surrounded by limited areas upon which houses could be built or lodges pitched. All about I found traces of native occupancy, and a dozen mortars, pestles, and pounding stones were picked up; these did not differ in character or material from the corresponding varieties of uten- 
sils reported from the deep gravels. The Neale affidavit states that the mortars and other implements therein referred to were found in the tunnel, some 1500 feet from the mouth of the mine, and 200 or 300 feet in beyond the margin of the lava-cap of the mountain, and hence beneath several hundred feet of the volcanic deposits that covered the country before the valleys of today began to be scored out (see figure 26).

Is it not more reasonable to suppose that some of the typical implements of the Indians living at the mouth of Montezuma mine should have been carried in for one purpose or another, imbedded in the gravels, and afterward dug up and carried out to the superintendent, than that the implements of a Tertiary race should have been left in the bed of a Tertiary torrent to be brought out as good as new, after the lapse of vast periods of time, into the camp of a modern community using identical forms?

I took pains to have $\mathrm{Mr}$ Neale tell me the story of the finds in all possible detail. The account as related in the work of Dr Becker had evidently passed out of his mind in large degree, as it had also passed out of my own. His statements, made from memory, and written down in my notebook during and immediately following the interview, were to the following effect:

One of the miners coming out to lunch at noon brought with him to the superintendent's office a stone mortar and a broken pestle which he said had been dug up in the deepest part of the tunnel, some 1500 feet from the mouth of the mine (see plate xxVIII). Mr Neale advised him on returning to work to look out for other utensils in the same place, and agreeably to his expectations two others were secured, a small ovoid mortar, five or six inches in diameter, and a flattish mortar or dish seven or eight inches in diameter; these have since been lost to sight. On another occasion a lot of obsidian blades, or spearheads, eleven in number and averaging ten inches in length, were brought to him by workmen from the mine. They had been found in what Mr 


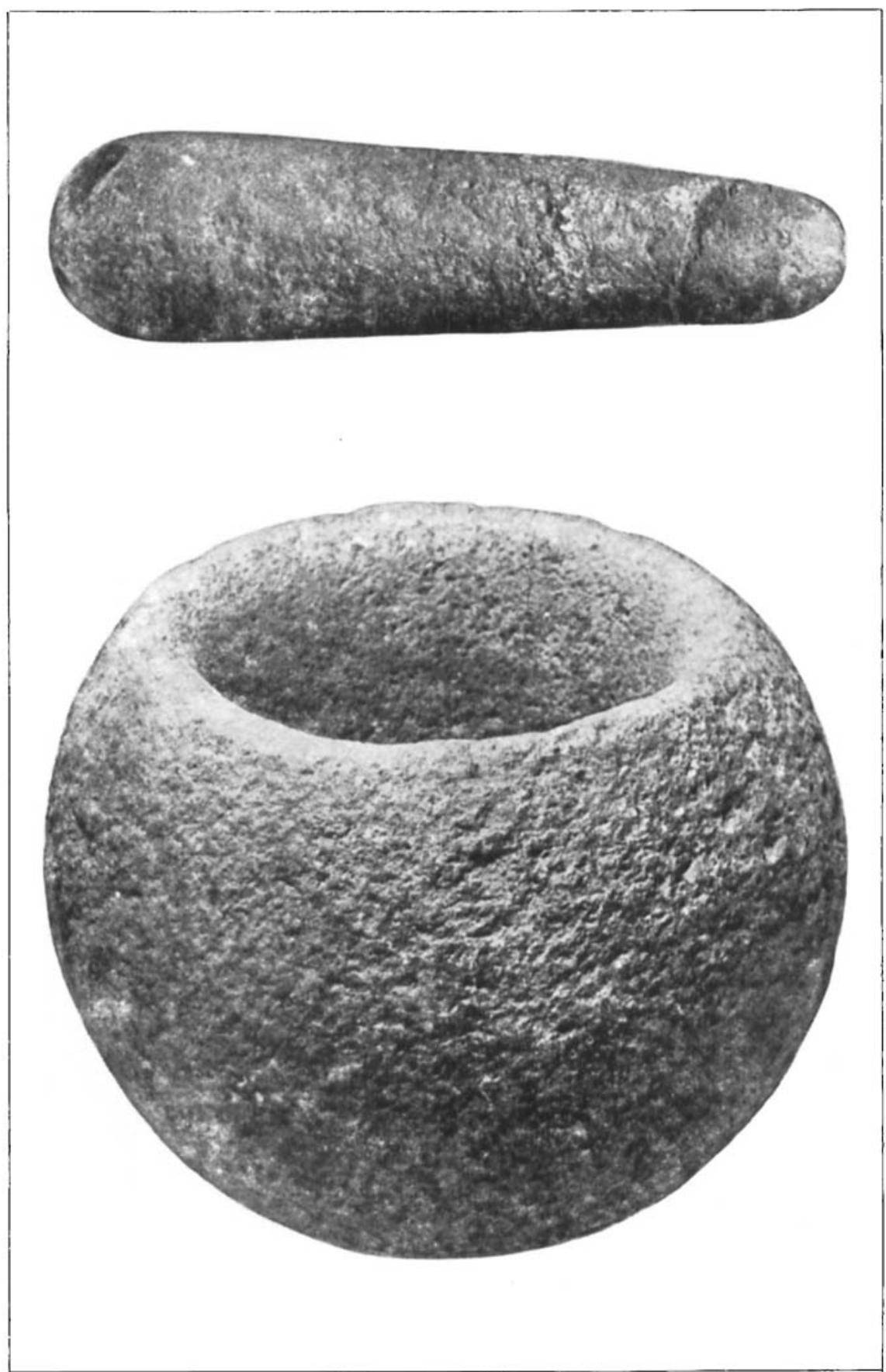

MORTAR AND PESTLE SAID TO HAVE BEEN FOUND IN MONTEZUMa MINE genEATH THE LaVA CAP OF TABLE MOUNTAIN 

Neale called a "side channel," that is, the bed of a branch of the main Tertiary stream, about a thousand feet in from the mouth of the tunnel, and 200 or 300 feet vertically from the surface of the mountain slope. These measurements were given as estimates only, but at the same time they were, he felt sure, not far wrong. Four or five of the specimens he gave to $\mathrm{Mr} \mathrm{C}$. D. Voy, the collector; the others also had been given away, but all trace of them had been lost. Mr Neale spoke enthusiastically of the size and perfection of these implements, and as he spoke drew outlines of long notched blades in the dust at our feet. Some had one notch (see figure 27), some had two notches, and others were plain leaf-shape blades.

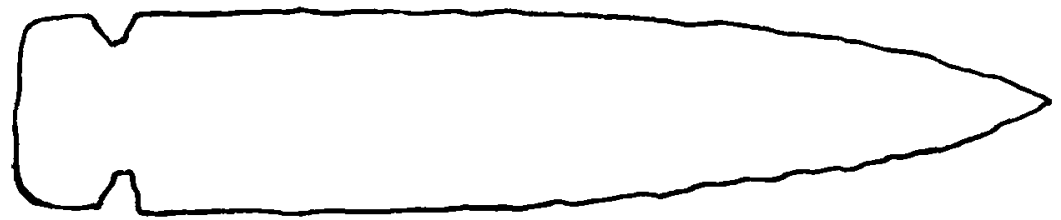

Fig. 27-Outline of obsidian implement said to have been found in Montezuma mine, as sketched by Mr Neale.

Desiring to find out more concerning these objects, he went on to say, he showed them to the Indians who chanced to be present, but strangely enough, they expressed great fear of them, refusing to touch them or even to speak about them; but finally, when asked whether they had any idea whence they came, said they had seen such implements far away in the mountains, but declined to speak of the place further, or to undertake to procure others. This statement by $\mathrm{Mr}$ Neale struck me at once as interesting and significant, and I was not surprised when a few days later it was learned that obsidian blades of identical pattern were now and then found with Digger Indian remains in the burial pits of the region. The inference to be drawn from these facts is that the implements brought to $\mathrm{Mr}$ Neale had been obtained from some one of the burial places in the vicinity by the miners, who found no spot too sacred to be invaded in the eager search for gold. An additional inference is that the Indians were aware of the 
origin of the specimens and were afraid of them because of the mortal dread that every Indian feels of anything connected with the dead. How the eleven large spearheads got into the mine, or whether they ever came from the mine at all, are queries that I shall not assume to answer, but that they did not come from the bed of a Tertiary torrent seems sufficiently clear; for how could a cache of eleven slender, leaflike implements remain unscattered under these conditions; how could fragile glass blades stand the crushing and grinding of a torrent bed; or how could so large a number of brittle blades remain unbroken under the pick of the miner working in a dark tunnel? -for, as Dr Becker states, "the auriferous gravel is hard picking, in large part it requires blasting."

That the affidavit of $\mathrm{Mr}$ Neale does not materially strengthen the evidence favoring antiquity I am now fully convinced. In his conversation with me he did not claim to have been in the mine when the finds were made, and a sworn statement vouching for the truth of assertions made by other persons, and these other persons unnamed miners, cannot be of value in establishing a proposition requiring proofs of the very highest order. That the other like finds of the Table Mountain region, recorded by Whitney and others, are equally open to criticism may reasonably be assumed.

The King Find.- The only bit of testimony that may not be challenged with impunity is the finding of a fragmentary pestle in the face of Table mountain two or three miles north of the Montezuma mine by $\mathrm{Mr}$ Clarence King, and reported in detail and with an illustration in Dr Becker's paper (page I93), already referred to. I sought the particular site from which the object was obtained, and passed up and down over every outcrop of rock on the slope, from the lava-cap to the pasture fields below, in the hope of finding some trace of human handiwork, but beyond the usual Digger mealing stones scattered over the surface, nothing was found. I tried to learn whether it was possible 
that one of these objects could have become imbedded in the tufa deposits in recent or comparatively recent times, for such an effect is sometimes produced by a re-setting or re-cementing of loosened materials, but no definite result was reached.

The unfortunate part about this very noteworthy feature of the testimony is that Mr King failed to publish it-that he failed to give to the world what could well claim to be the most important observation ever made by a geologist bearing upon the history of the human race, leaving it to come out through the agency of Dr Becker, twenty-five years later. That he did not promptly give it to his associates engaged in researches regarding human antiquity might be construed as indicating lack of confidence in the verity of his own observations.

\section{THE CALAVERAS SKULL}

Notwithstanding the fact that the finds of stone implements in intimate relation with the Auriferous Gravels furnish the great body of testimony upon which a Tertiary man is predicated, they have attracted but slight attention from the public as compared with the reputed discovery of human remains, and more especially the discovery of the so-called Calaveras skull in a mine shaft at Altaville. The prominence of the latter find is due largely to the fact that it is the only specimen of its kind that has escaped oblivion. This relic has been the subject of much disputation, but I shall not stop here to cite or review the literature. It may be observed, however, that the general trend of sentiment and even of scientific opinion has been adverse to the specimen as proof of antiquity; at the same time there is a very important contingent of scientific men, especially those grouped around the original apostle of antiquity, Whitney, who cling tenaciously to the idea of a Tertiary man. As long as this condition exists it is manifestly unwise to attempt to pass over the evidence of the Calaveras skull, as some are inclined to do, with the assertion that it is insufficient and hence unworthy of consideration. 
In plate XXIX, $a$, is presented a view of the skull as it appeared when first brought to the attention of Professor Whitney in I866, and in plate XXIX, $b$, as it appeared after having been cleaned up by $\mathrm{Dr}$ Wyman at Cambridge. The former is from a photograph made by Alonzo Rhodes, at Murphy's, California. Being faded, the photograph had to be redrawn for engraving, hence the cut has not the merits of a photograph directly reproduced. The latter is copied from a lithographic plate published by Whitney in his work on the Auriferous Gravels and is manifestly defective, quite a little of the character and natural ruggedness having been lost by the draughtsman. The specimen is now preserved in the Peabody Museum at Cambridge, and comprises about three-fourths of the skull. Enough remains, however, to enable the craniologist to determine something of the physical characteristics and hence of the mental equipment of the person to whom it belonged. The account of the skull given by Whitney includes a careful description by Jeffries Wyman, one of the highest American authorities of the time. The whole subject is presented in such manner as to convey to the unprejudiced mind an impression that the skull is a genuine and well authenticated relic of antiquity.

The skull is said to have been taken from the Mattison \& Company mine on the gentle slope of an oblong rounded hill, some three hundred feet in height, situated in the suburbs of Altaville, a mile or more northwest from the important mining town of Angels. This shaft is still open, a roomy rectangular well some one hundred and thirty feet deep, cut in beds of compact, tenacious, volcanic rock and underlying strata of varying character, and has undergone little change in the thirty-three years that have passed since the reported finding of the skull. A road once passed the mine and continued round the hill, but it is now nearly obliterated, and all traces of buildings are gone from the slope which is diversified only by occasional old mine dumps and a growth of scrubby trees. It was my intention to descend into 


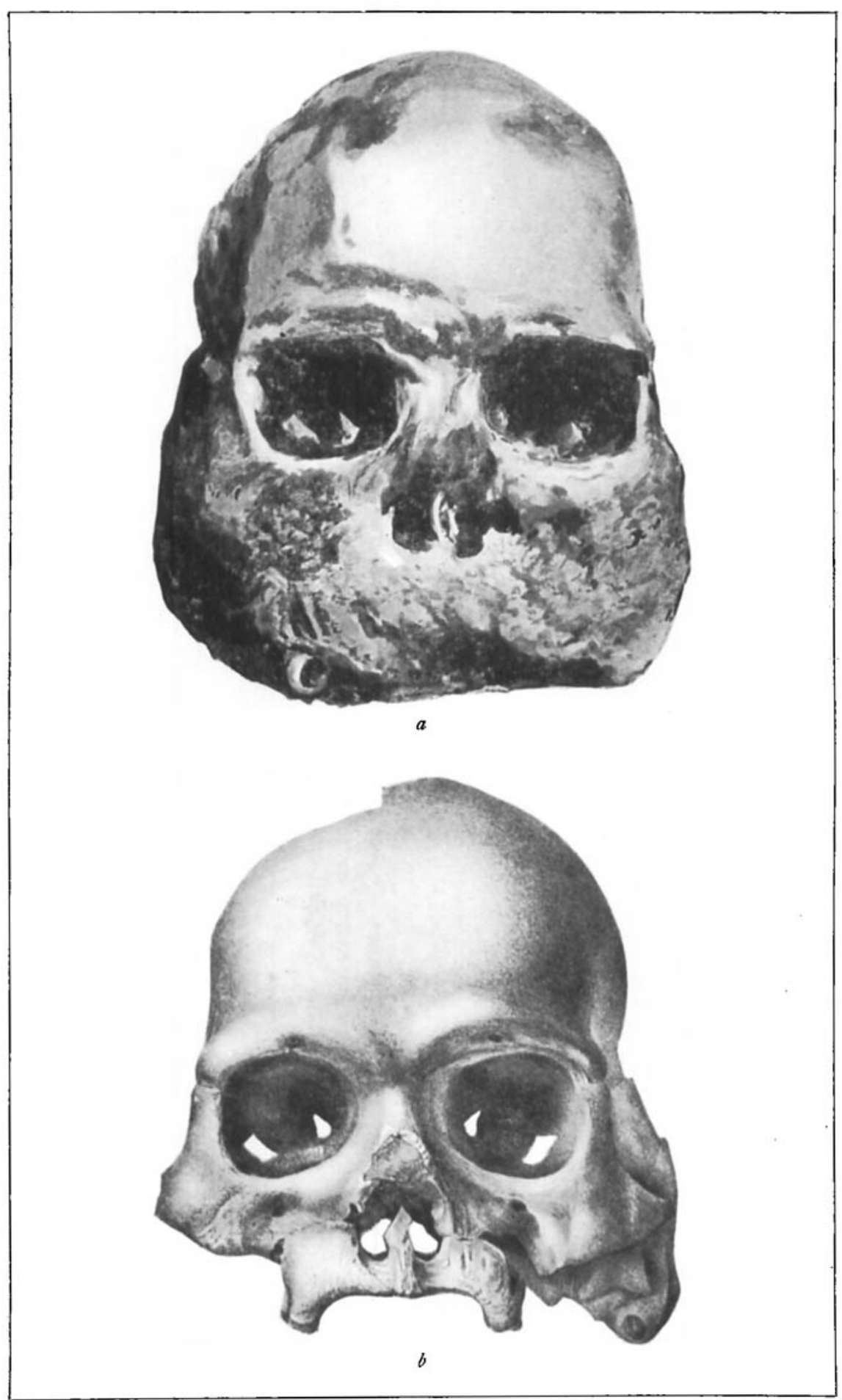

THE CALAVERAS SKULL.

a. Copied from a photograph made by Alonzo Rhodes at Murphy's. B. From Whitney's lithographic plate. 

the shaft and examine the formations, but there was no time to spare for erecting the necessary windlass. It is important that the formations at the depth from which the skull is said to have come should be examined for comparison with the material adhering to and partially filling the skull, and this work I hope to take up at an early date.

Whitney's Account of the Skull.-According to Whitney's account the skull was taken from the shaft of Mattison \& Company's mine in February, I866. Mr Mattison with his own hands took the skull from near the bottom of a bed of gravel, one hundred and thirty feet from the surface, and within a few feet of the bed-rock-the crystalline slates in which the Tertiary river had carved its channel. It was "lying on the side of the channel [of the Tertiary river] with a mass of driftwood, as if it had been deposited there by an eddy of the stream, and afterward covered over in the deposit of gravel by which bed No. 8 was formed."

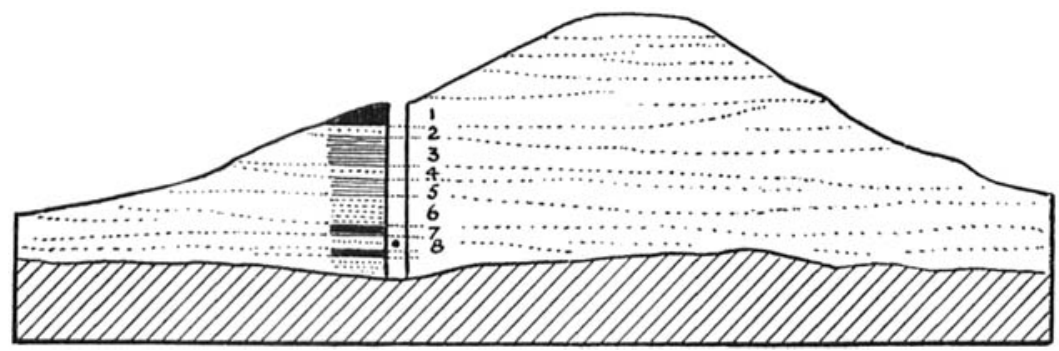

FrG. 28-Section of the deposits exposed in Mattison mine, Bald mountain. The skull is said to have been found in stratum No. 8.

Figure 28 reproduces a section obtained by $\mathrm{Mr}$ Edward Hughes, of Stockton, in connection with an unpublished paper on the Calaveras skull, written by $\operatorname{Dr} A$. S. Hudson. It seems to correspond in every essential feature with the section published by Whitney, and with a section furnished me together with photographs of implements and human and animal remains from the region, by Mr R. E. C. Stearns of Los Angeles.

According to Whitney, Mr Mattison did not recognize the AM. ANTH. N S., I-40. 
object as a skull when taken from the gravel, but "thought it to be a piece of the root of a tree." Mr Scribner also stated that when the skull was brought to him "it was so imbedded and incrusted with earthy and stony material that he did not recognize what it was." Mr Mattison, however, seems to have considered the curious gravel-covered lump of sufficient interest to note carefully the conditions under which it was found, "as if deposited in the eddy of a stream," and soon afterward carried it in a bag to Angels, presenting it to $\mathrm{Mr}$ Scribner, merchant and Wells Fargo \& Co's agent. It was not until a clerk in $\mathrm{Mr}$ Scribner's store, probably Mr Matthews, cleaned off a portion of the incrusting material, that any one suspected that the object was a human skull. Soon after this the skull was sent to Dr William Jones, at Murphy's, twelve miles away. The Doctor was an enthusiastic collector of natural history specimens, and, regarding the skull as having more than ordinary interest, wrote to the office of the State Geological Survey in San Francisco, describing the specimen. A few days later, on June 29 th, at the request of $\mathrm{Mr}$ Wm. M. Gabb, paleontologist of the Survey, the Doctor forwarded it to San Francisco.

Professor Whitney soon afterward visited Calaveras county and proceeded to make careful inquiries into the origin of the skull. He visited $\mathrm{Mr}$ Mattison and others, obtaining the statements embodied in his report, and became convinced that the skull had been found precisely as described by Mr Mattison, and that its subsequent history was correctly given by $\mathrm{Mr}$ Scribner and Dr Jones.

When delivered to Professor Whitney the base of the skull was "imbedded in a conglomerate mass of ferruginous earth, water-worn pebbles of much altered volcanic rock, calcareous tufa, and fragments of bones. This mixed material covered the whole base of the skull and filled the left temporal fossa, concealing the whole of the jaw. A thin calcareous incrustation appears to have covered the whole skull when found; portions of it had 
been scaled off, probably in cleaning away the other material attached to the base" (plate XXIX,a). Together the two eminent professors carefully chiseled away the foreign matter adhering to its base, so as to expose the natural surface of the skull, leaving it in its present state (plate XXIX, b). The skull was found to be that of a very old person, the teeth being gone, and the alveoli nearly absorbed. The lower jaw is gone, and the cranium is far from perfect; portions of the occiput are missing, and the remaining portions are badly fractured. Professor Whitney expresses his views as to how the specimen came to be thus rudely fractured, and as to subsequent events in its history, in the following words :

"The skull was unquestionably dug up somewhere, and had unquestionably been subjected to quite a series of peculiar conditions. In the first place, it had been broken, and broken in such a manner as to indicate great violence, as the fractures go through the thickest and heaviest parts of the skull ; again, the evidence of violent and protracted motion, as seen in the manner in which the various bones are wedged into the hollow and internal parts of the skull, as, for instance, the bones of the foot under the malar bone. The appearance of the skull was something such as would be expected to result from its having been swept, with many other bones, from the place where it was originally deposited down the shallow but violent current of a stream, where it would be exposed to violent blows against the boulders lying in its bed. During this passage it was smashed, and fragments of the bones occurring with it were thrust into all the cavities where they could lodge. It then came to rest somewhere, in a position where water charged with lime salts had access to it, and on a bed of auriferous gravel. While it lay there the mass on which it rested was cemented to it by the calcareous matter deposited around the skull, and thus the base of hard mixed tufa and pebbles which was attached to it when it was placed in the writer's hands was formed. At this time, too, the snail crept in under the malar bone, and there died. Subsequently to this the whole was enveloped by a deposit of gravel, which did not afterwards become thoroughly consolidated, and which, therefore, was easily removed by the gentlemen who first cleaned up the specimen in question, they only removing the looser gravel which surrounded it." (P. 272.) 
In cutting away the incrusting material, several fragments of bones were found: some that might have belonged to the same individual to whom the skull pertained, while others evidently belonged to a smaller person. Besides these there were bones of some small mammal, a small snail shell of the species Helix mormonum, a small wampum or shell bead, and some bits of charcoal.

Chemical examinations by $\mathrm{Mr}$ Sharpless developed the fact that nearly all the organic matter of the bone had disappeared and a large portion of the phosphate of lime had been replaced by the carbonate, indicating a fossilized condition; a trace only of organic matter remained. From Dr Wyman's report, published in Whitney's paper, we learn: Ist, "That the skull presents no signs of having belonged to an inferior race. In its breadth it agrees with the other crania from California, except those of the Diggers, but surpasses them in the other particulars in which comparisons have been made. This is especially obvious in the greater prominence of the forehead and the capacity of its chamber. 2nd, In so far as it differs in dimensions from the other crania from California, it approaches the Esquimaux." (P. 273.)

Portions of the above statements will be referred to in some detail farther on.

Information from Local Sources.-During my short visit to the district $I$ found only a few men who could claim personal knowledge of the skull and of the people most directly concerned in its discovery and immediately subsequent history. Scribner and Jones are dead, and others have removed from the district. At Big Trees, eighteen miles above Murphy's, I found $\mathrm{Mr}$ J. L. Sperry, who kept the hotel at Murphy's and was Whitney's host while the latter was visiting that section. He proved to be a good friend of the Professor, and a believer in the correctness of his views regarding the skull. His hotel faced the office of $\mathrm{Dr}$ Jones, to whom the skull was sent from Scribner's, and he told me that one day as he was standing in the door of his hotel $\mathrm{Dr}$ 
Jones came out of his office opposite, and with characteristic imprecations threw a broken skull into the middle of the street. Called upon to explain, the Doctor said that the skull had been brought to him as a relic of great antiquity, but that he had just discovered cobwebs in it, and concluded that he had been made the subject of one of Scribner's practical jokes. Afterward the Doctor picked up the specimen again and carried it into his office, saying that perhaps he had been too hasty, and that he would give it further consideration. Shortly afterward the skull was sent to San Francisco, and a little later Whitney returned to Murphy's and proceeded to make inquiries as to its origin. $\mathrm{Mr}$ Sperry drove him to Angels Camp to see Mattison and to obtain from him a statement regarding the discovery of the skull. The statement was obtained, and satisfied Whitney as to the genuineness of the find. The opposition to the evidence was, he said, mainly from religious prejudices and, he thought, had no solid foundation.

Others at Murphy's were familiar with the story, often told and retold, but all were unbelievers and took great pleasure in telling of the practical jokes perpetrated by Scribner and his coterie upon their friends, and upon Dr Jones in particular. In general the versions of the story of the skull were much alike, showing a common origin but having individual variations characteristic of memory recitals. I talked with J. L. N. Shephard, C. A. Curtis, W. J. Mercer, E. H. Schaeffle, and others well informed on the events of the early days; and the statement by $\mathrm{Mr}$ Joseph Shephard, a prominent local engineer, made in writing to $\mathrm{Mr} \mathrm{H}$. W. Turner of the U.S. Geological Survey, may serve to indicate the general trend of these accounts and the character of the persons connected with the story of the skull. His statement is as follows:

"When the skull was found in Mr Madison's (Mathewson's) shaft, there lived in Angels three men, John Scribner (merchant), William Coddington (ditch owner), and Ross B. Coons (saloon 
keeper). In Murphy's there lived William Griffiths (ditch superintendent) and Dr Jones, all good friends one with another, and all owners in the Union Water Company's ditch, except probably Coons. Griffiths delivered the skull to $\mathrm{Dr}$ Jones, how long after Madison (Mathewson) found it I know not, but when Dr Jones found cobwebs in it he threw it out of his office, but decided to take it back again. From this on, I suppose the history of the skull is well known. I recollect that when the public began to talk about it, the common belief was that Scribner, Coddington, and Coons, of Angels, and Griffiths of Murphy's, knew how the skull got into Madison's shaft, and used it simply to play a practical joke on their friend Dr Jones; and, as has been said, they were capable of doing it. There is no doubt that Madison was sincere in his belief that the find was genuine."

As all authentic details relating to the history of the skull are valuable, the following extracts are made from a paper written several years ago by $\operatorname{Dr}$ A. S. Hudson, of Stockton, now deceased. The manuscript was obtained for me by Prof. Edward Hughes of Stockton, and being imperfectly finished and somewhat erratic in treatment, it is not considered advisable to publish it in full; but such parts as relate to his visit to the mining segion are interesting and suggestive and may be given.

In 1883 Dr Hudson corresponded with Dr John Walker of Sonora, who in a letter stated that he had taken a lively interest in the skull, opposing its claims to authenticity, and had endeavored to convince Whitney that he was doing a great injury to science by accepting the evidence. He induced a friend to convey to Whitney the information that "the specimen was found at Salt Spring valley, near the surface, and not in a mine on Bald mountain, but Whitney treated the information discourteously." Continuing, the letter stated that "about the time the discovery was made several caves were found and skulls of the same description taken from them; they were evidently the burial places of Digger Indians. No one about the diggings supposed otherwise." 
Later, Dr Hudson visited Dr Walker at Sonora, but made up his mind that the Doctor had little actual knowledge of the matter, and slight foundation for his assertion "that the whole affair was a abrication and a joke on Whitney." Going on to Angels, he interviewed Scribner and Mattison. He was most favorably impressed with $\mathrm{Mr}$ Scribner, who in a dignified and convincing manner assured him that Dr Walker was wrong, and that no deception whatever had been practiced. Having gathered all the facts in the case that Scribner cared to impart, the Doctor visited Mr Mattison, "the veritable miner and supposed discoverer of the head of our inquiry. Fortunately he and his wife were found at home, and without hesitation proceeded to relate the story, with the steps which brought the find to light. The man's wife had a better memory than he, and she seemed to be equally well informed about it. Thus I was furnished with two witnesses in one home. It was said: Late in the year 1865 he, Matson, began to dig for gold. He sank his shaft in Bald mountain and not Table mountain. . . . Reaching the depth of 128 feet the industrious miner struck some old wood. Here in neighborly pose the remains of vegetable and animal [human] life were found. They were found imbedded in gravel and a kind of cement, which he thought was wood also. Taking the round or globular dirt-covered bundle home, he said nothing about it to his family, but kept it in his house a year or more. Here I showed Matson and his wife the figure or cut copied from Professor Whitney's book. . . . Mrs Matson at once recognized the picture as representing the specimen in question. It was said the cemented gravel so adhered to it as to fill out the back head and make it look a natural occipital portion."

Account Given by $\mathrm{Mr}$ Scribner.-Dr Hudson left Calaveras county "perplexed and discouraged." The stories told him seemed "incomplete and incoherent." "But," he continues, "some two weeks later Mr Scribner called at our office in Stockton with the welcome errand of a refreshed memory, and with 
additional facts fitting into the body of the narrative making it more consistent. . . . It seems, as time went on, Mrs Matson, an orderly housekeeper, began to take a dislike to that untidy thing --an unwashed dead head in her house, and made complaint. It was more in the way than of use or ornament, and she decided to get rid of it. Thereupon her husband, like a proper acquiescing partner in life, carried it to $\mathrm{Mr}$ Scribner's store, where at the same time the Wells Fargo Company had its business office. $\mathrm{Mr}$ J. C. Scribner and his partner, Mr Henry Matthews, now became the uninvited custodians of the topmost part of an aged and unknown man. . . . This man Matthews had a common failing among people, he was fond of liquor, and sometimes indulged his taste to excess. Some few days or maybe weeks prior to the advent of the skull at Scribner's, Matthews, not feeling well, paid a visit to $\mathrm{Dr}$ Jones, a worthy physician at Murphy's, consulted him in regard to his health, and obtained from the Doctor a prescription and medicine. The medicine proved rather strong; it depleted the patient rapidly and produced unlooked-for discomfort. As he grew weaker and impatient under the continued action of the purge, it made Matthews swear, he swore at the unholy medicine and at the $\mathrm{d}-\mathrm{d}$ outcast of a doctor who gave it. The natural result was he became cross towards Dr Jones. Not to lose sight of the skull, we note that as soon as Mr Scribner saw the dirty rotted remains of old mortality before him, so soon he decided it was out of his line, and he did not want the offensive thing about. But Matthews took to it instinctively and at once. He thought that it with some half-rotted and halfpetrified pieces of wood and a few lumps of native ore might do to embellish Dr Jones's cabinet of geological and natural history curiosities. Therefore, they, the uneasy head and the rest, were immediately dumped into an empty potato sack and sent to $\mathrm{Dr}$ Jones at Murphy's. On the same day it came without note, comment; or message, and Esculapius opened the sack and took out its contents one by one. After a short inspection of the specimens of 
ancient remains, he, with a pious imprecation on the head of the other fellow and his impudence, gave it a toss into the back yard. There the bony thing, which had long resisted the tooth of final destruction, was again exposed to a more quickening action of hurtful elements. There in the damp of rain and mildew it remained for many months unnoticed. There it is quite likely, indeed probable, that the little Helix mormonum which can be seen photographed at the right hand base of the figure [plate XXIX, $a$ ] became attached.

"At length Mr Matson, in one of his occasional visits to Murphy's, saw, like a familiar ghost, his old acquaintance, the same old head. He inquired of Dr Jones where he got it, not knowing what disposition Mr Scribner and company had made of it. Learning for the first time that several months anterior thereto Matson had dug the head out of his own shaft 128 feet below the surface of the ground, the Doctor then suspected it might turn out something of interest. These unlooked-for facts at once invested the dirty top-knot with new and even profound considerations. It was soon photographed by $\mathrm{Mr}$ Alonzo Rhodes of Murphy's, and the negative was sent to Mr Shew at San Francisco where pictures were printed. The attention of Professor Whitney was now called to the resurrected head. He in company with Mr Matson, the miner, visited the now old and abandoned miners' shaft. They found it partly filled with water and dirt, which was soon pumped dry. Mr Matson pointed out on the wall of the bank the precise spot the interesting object lay in conjunction with fragments of wood. The wood he thought was a fragment from quite a large tree. From this spot Whitney told Mr Scribner he gathered gravel and carefully compared it with that scraped from the skull. They proved identical one with the other. It seemed the gravels in the different layers above were of other kinds. This fact precludes the possibility of designing person or persons securing the object ' from Salt-Spring valley' (as opposers have asserted), and dropped it down the 
shaft. I inquired of $\mathrm{Mr}$ Matson how it came to be rumored that the skull was taken from 'mud spring in Salt Spring valley' and thence conveyed to his mining shaft. He answered that - Before I began mining at that place and several years back into the decade of 1850 , a Mrs Hoffman had gathered several skulls from Salt Spring valley, a place some twelve miles distant from Angels, and had them on exhibition in a sort of cabinet collection.' One of these heads had been fractured and crushed on the left parietal bone, the line of fracture running to the temple. Some similitude or relationship between these and the Calaveras head was believed to exist. But how or in what manner nobody could tell, for none knew.

"It may be proper here to say that Mr Matson is a plain, hard-working day laborer, a blacksmith by calling. He seems to be a very honest-appearing man. He evidences no disposition to magnify, falsify, or to depart from the correct line of truth. Here ends all there is or, as far as I can learn, ever was, about the so-called 'joke' over the Calaveras skull; except its occasional rehearsal, and the more important fact that it was a joke by Matthews on Dr Jones and not on Professor Whitney.

"As mentioned above, the animus of it was not to play upon the spirit of scientific inquiry, nor to deride native anthropological study; but it was a trick sprung on the spur of the moment in a spirit of humorous hilarity by Matthews, Scribner's partner in business. But the Doctor, being the victim, did not see the point."

This story is interesting as emanating from Mr Scribner, who, according to many accounts, knew more than any other person regarding the origin and early movements of the skull.

At Angels Camp I visited Mr Rasmussen, a former business partner of Mr Scribner's, but he had given the matter little attention and did not know whether Scribner believed in the authenticity of the skull or not; but $\mathrm{Mr}$ George Stickle, present postmaster of the village, showed a decided interest in the 
matter. He had been closely associated with the Scribner coterie in the early days, and knew all the principal people of Angels Camp almost from its foundation. It is his belief that the whole affair grew out of the "joshing" proclivities of his fellow-townsmen, and he laughed heartily as he recited the circumstances of the finding and subsequent misadventures of the so-called Calaveras skull. He went on to state that the skull had been in his store several weeks before it fell into the hands of his fun-loving associates; together with a companion specimen it had been brought to him from a burial place in Salt Spring valley, twelve miles west of Angels, by Mr J. I. Boone. I was extremely sorry not to be able to visit the supposed place of origin of so famous a specimen, for the stories seemed sufficiently circumstantial to warrant scientific attention.

Is it a Changeling Skull? - According to some of the current stories of the region the skull was placed in the mine by one of Mattison's neighbors merely as a joke, while he was at home for dinner, and he is supposed to have found it where it was buried among the debris at the bottom of the shaft. This may or may not be true; at any rate, as no names are given the statement cannot be verified.

The remark made by $\mathrm{Mr}$ Stickle and others that the skull obtained by Whitney did not come from the Mattison mine or through Mattison at all, may also have little value as evidence; but it is suggestive, and gives rise to a legitimate inquiry as to the possibilities in the case. There were ancient skulls in plenty in this region in early times, and the valley and county received their name Calaveras-which, in Spanish, signifies skulls-from this circumstance.

The Indians of the high sierra do not bury their dead, but cast them into pits, caverns, holes in the rocks, and deep gorges. Generation after generation follows one another into these gaping Golgothas where, in a confused heap along with rude personal belongings and sacrificial offerings the bodies decay and are 
covered by accumulating debris and deposits from running or percolating waters. As mining operations went on these burial places were cleaned out and the bones became public property. Skulls were plentiful at Angels in those days, as many persons testify. There is, therefore, a chance that the skull sent to $\mathrm{Dr}$ Jones was not the one found by Mattison, but a cement-covered specimen derived from some other source as Stickle states and Scribner suggests. Certainly there were several months during which little or no trace was kept of the lump of conglomerate carried home by Mattison. The usual answer to the suggestion that there might have been a changeling skull is that the Calaveras specimen is not a common skull, but a fossil, and must have come from gravel deposits identical with those in Bald mountain if not actually from the Mattison mine, and that its great age is thus sufficiently established. But who shall say that many of the skulls found about Angels Camp were not obtained from comparatively recent burials in surface exposures of auriferous gravels or in other gravels where the conditions were such as to permit of rapid cementation, giving rise to phenomena identical with those observed in the Calaveras skull?

Testimony of the Skull Itself.-Recognizing the fallibility of human testimony and the consequent difficulty of surely connecting the Calaveras skull with the gravels in place in Bald mountain, the characteristics and condition of the skull itself have been appealed to by advocates of its authenticity. The report on its physical characters, however, made by Jeffries Wyman, does not in any way aid the case. It is to be expected that a Tertiary skull would in some manner show or suggest inferior development, but this skull appears to represent a people superior to the present Indian tribes of the region. Again, it is to be expected that some distinctive characteristic, some race peculiarity, would appear in the skull of a people separated by uncounted centuries from the present; that it would be longer or shorter, thicker or thinner, or more or less prognathous than the Indian skull, but 
Wyman has nothing more startling to say than that "in so far as it differs in dimensions from the other crania from California, it approaches the Esquimaux." This vague variation is just as likely to be an individual peculiarity as a racial character. It need not be regarded as strange that the skull should be superior to the average Digger cranium, for no anthropologist would be willing to affirm that the Diggers are the first and only people who have occupied this region during the present geological period. The chances are that the Shoshonean stock, to which these Diggers belong, is a somewhat recent intruder on the western slope of the sierra in California; and more than one of the present or past groups of Pacific Coast Indians may have passed this way at some period in their history. The practical identity of the skull with modern crania speaks very eloquently against extreme antiquity.

Professor Whitney lays much stress upon the fact that the specimen is undoubtedly a fossil. "Chemical analysis proves that it was not taken from the surface, but that it was dug up somewhere, from some place where it had been long deposited, and where it had undergone those chemical changes which, so far as known, do not take place in objects buried near the surface." If there was a trick on the part of fun-loving miners, "they must themselves," he adds, " have obtained from somewhere the object thus used; and as all the diggings in the vicinity are in gravels intercalated between volcanic strata, it becomes, really, a matter of but little consequence, from a geological point of view, from whose shaft the skull was taken." ${ }^{1}$ It would appear that Whitney failed to notice that although the gravels were originally wholly intercalated with strata of volcanic materials, they have been exposed in many places by the erosion of valleys, that they outcrop on the hillsides and lie uncovered in the valleys, and that any of the modern tribes may have buried their dead in previously undisturbed Tertiary river gravels. I learned of more than one 1 Auriferous Gravels, p, $27 \mathrm{r}$. 
case of this kind; and when so buried, there is no reason why the osseous remains, especially if deeply covered by over-deposits of shifting materials, should not have assumed, in a comparatively short period of time, exactly the conditions characterizing a fossil. Such comparatively recent burials in exposed very ancient river gravels may readily have taken place within less than a thousand yards of the Mattison mine.

The term fossil really signifies little in this connection, although assumed by some to signify much. No one would venture to assert that a skull might not lose nearly all its organic matter, and that a large portion of the phosphate of lime might not be replaced by the carbonate in a few hundred years if the conditions were reasonably favorable to the change. That such changes do not readily take place very near the surface is probably true; but we must not lose sight of the fact that, setting aside the possibility of the accumulation of deep overplacements, burial in caves and pits was practiced in this section and that these receptacles are sometimes of very considerable depth. Bodies cast in are rapidly covered up and are subject to just such conditions as those favoring fossilization.

It should be noted that silicification of the osseous matter of the skull is not mentioned; iron and lime are cementing agencies merely. Iron is everywhere and its reactions are rapid; and in a region abounding in limestone formations calcareous matter is freely dissolved, carried, and deposited by the waters. The conditions characterizing the skull are just such as might be expected in a skull coming from one of the limestone caves, crevices, or pits of the district. The thin film of calcareous matter coating the skull and extending throughout the porous filling makes it heavy, but does not necessarily indicate a prolonged period of inhumation.

It would appear from statements made by Scribner (in Hudson's paper, already quoted) that Whitney descended into the mine and examined the gravel bed from which the skull is said to 
have been obtained, but in his monograph the latter states that he failed to accomplish this on account of the water in the mine. He says that "the excavation has remained filled with water during the whole time since the skull came into my possession." (Page 27I.) However, some one must have succeeded in overcoming the difficulty, as $\operatorname{Dr} W$. H. Dall states ' that while in San Francisco in 1866 he compared the material attached to the skull with portions of the gravel from the mine and that they were alike in all essentials. But even if the material from the mine is like that attached to the skull nothing is proved, as the same may well be true of materials from many parts of the Angels district. The peculiar agglomeration of earth, pebbles, and bones is readily explained by referring to conditions existing in the limestone caverns and crevices of the region where the calcareous accretions bind together bones, gravel (very generally present), cave earth, and whatever happens to be properly associated, in just such manner as that illustrated in the specimen under discussion.

Again, much stress is laid on the fact that the skull obtained by Whitney "had been broken in such a manner as to indicate great violence," as if subject to severe blows while swept by a torrent over a bed of bowlders. When it is remembered that the fractures exhibited by the skull are fresh and sharp, this highly imaginative statement (previously quoted in full) loses its force, for the tossing in a torrent over bowlders would not only have bruised and abraded the sharp edges of the bone, but the loose earth, broken bones, wampum, and shells, instead of being jammed into the skull would have been quickly dislodged and widely scattered by the rushing waters. The facts are, and may be stated emphatically, that the conditions of fracture and the impacting of bones of more than one individual along with other miscellaneous articles in the cavities of the skull, are just such as would occur as a result of pitching body after body into an

${ }^{1}$ Proceedings of the Acadimy of Natural Sciences of Philadelphia, 1899. 
Indian burial pit where young and old were jammed into a conglomerate mass and covered with earth, gravel, and stones.

The presence of a wampum bead imbedded with the earth, bones, and pebbles in the skull is a strong argument against antiquity. It is not claimed that this shell bead is fossilized, and it would seem that it resembles in every way-size, shape, manner of boring, and degree of elaboration-the concavo-convex beads made from clam shells and worn by members of nearly every Indian family in California. That a Tertiary people should have made and worn the identical form seems highly improbable.

The small snail shell, the fragile Helix mormonum, found also in the skull, is much more at home in a modern burial place than in the torrent-swept bed of a Tertiary river. The species is recent, and I am not aware that it has been found in Tertiary formations.

It thus appears that the so-called Calaveras skull exhibits nothing in its character, condition, or associated phenomena incompatible with the theory of recent origin, and very much that may be justly construed as favoring that theory.

The Skull at Cambridge.-On returning to the East I took the first opportunity of visiting Cambridge for the purpose of examining the Calaveras skull. Professor Putnam very kindly removed the specimen from its resting place and permitted me to examine it at leisure and to handle the loose materials-the limecemented earth, the bits of bone, and the shell bead-detached by Professor Wyman. He preferred, however, that I should not attempt to describe the relics, as he had in view the publication of a paper giving his views and an exhaustive chemical and comparative study of the skull. This idea I hope to see him carry out at an early day, as it is manifestly the duty of the custodian of so important a relic to place it freely and fully before the world. If there is anything to add to what Whitney and Wyman have already said, the present generation of anthropologists should have the benefit of it. It is now thirty-three years since the specimen was carried to Cambridge. 
I looked forward with much interest to this glimpse of the specimen about which so much has been said and upon which so much has been predicated, and was prepared to be duly impressed with its character as a fossil, but I was distinctly disappointed. The importance of the skull as an index of antiquity has been over-estimated. I find myself confirmed in the conclusions forced upon me by a consideration of the evidence already presented, namely, that the skull was never carried and broken in a Tertiary torrent, that it never came from the old gravels in the Mattison mine, and that it does not in any way represent a Tertiary race of men. If the existence of Tertiary man in California is finally proved, it will be on evidence other than that furnished by the Calaveras skull.

\section{SUMMARY}

A brief summary of the arguments for and against the great antiquity of man in California may well be presented here for convenience of reference. The principal considerations arrayed in support of the affirmative are as follows :

(I) During the three or four decades succeeding the discovery of gold in California the miners of the Auriferous belt reported many finds of implements and human remains from the mines. The formations most prominently involved are of Neocene age; that is to say, the middle and later portions of the Tertiary.

(2) Most of the objects came from surface mines, but some were apparently derived from tunnels entering horizontally or obliquely and to great depths and distances beneath mountain summits capped with Tertiary lavas, leading to a belief in their great age.

(3) The finds were very numerous and were reported by many persons, at various times, and from sites distributed over a vast area of country. They were made by inexpert observers-by miners in pursuit of their ordinary calling,-but the statements made by them are reasonably lucid and show no indications of intentional exaggeration or attempted deception. 
(4) The stories as recorded are uniform and consistent in character and the objects preserved are, it is claimed, of a few simple types, such as might be expected of a very ancient and primitive people. The evidence, coming from apparently unrelated sources, is described as remarkable for its coherency.

(5) The reported finding of an implement in place in the late Tertiary strata of Table mountain by $\mathrm{Mr}$ Clarence King, a leading geologist, gives countenance to the reports of inexpert observers.

(6) The osseous remains recovered are, in some cases, said to be fossilized, having lost nearly all their animal matter, and some are coated with firmly adhering gravels resembling those of the ancient deposits. These conditions give rise to the impression of great age.

(7) The remains appear to be associated with flora and fauna indicating conditions not antagonistic to the existence of the human species.

(8) The evidence as presented by Whitney and others seems abundant and convincing, and many scientific men have accepted it as satisfactory proof of a Tertiary man in America.

On the other hand numerous considerations are urged against great antiquity, as follows:

(I) It is held that the strength of testimony should be proportioned directly to the magnitude of the propositions to be supported, and that this case requires proofs of a higher order than have as yet been presented.

(2) The existence of a Tertiary man, even of the lowest grade, has not yet been fully established in any country, and this California evidence, therefore, stands absolutely alone. It implies a human race older by at least one-half than Pithecanthropus erectus of Dubois, which may be regarded as an incipient form of human creature only. The finds reported indicate a Middle Tertiary people well advanced in the elements of culture; and culture, especially in the earlier stages, is necessarily of exceedingly slow 
growth. The Pithecanthropus of California would have to be looked for somewhere in the early Tertiary if not in a preceding period. The burdens thus thrown upon the Auriferous Gravel evidence are enormous.

(3) The proposition that a Tertiary man could survive to the present time surpasses belief. The physical and biological changes in the region have been profound and far-reaching. The western half of the continent has been twice or thrice remodeled since Middle Tertiary times, and every known species of plant and all species of the higher forms of animal life have been obliterated. Evidence based on random and inexpert observations is not sufficient to establish such a proposition.

(4) If it could for a moment be admitted that man did survive throughout the ages and continental transformations, it appears quite impossible that his physical characters and his culture should have remained unchanged. It is equally impossible that a modern race could have sprung up duplicating the man of a million years before in every essential particular.

(5) Examination of the human relics reported from the gravels fails to give support to the claim of antiquity. Fossilization of the osseous remains, upon which so much stress has been laid, may have taken place in comparatively recent times. The chemical changes noted are such as might be expected to characterize remains buried for a few hundred years in the deep pits and caverns of the region. The crania recovered are identical in character with recent crania.

(6) Objects of art from the Auriferous Gravels are said to be of the most primitive character, and, in large measure, peculiar to the gravels. When critically examined, however, they are found to belong to the polished stone age and to duplicate modern implements in every essential respect. They are such as may have fallen in from Indian camp sites or been carried in by the Indians themselves. They are made from varieties of stone belonging to formations ranging from the oldest to the youngest found in 
the district, and have been shaped by the ordinary processes employed by our aborigines. They evidently served purposes identical with corresponding implements of our Indian tribes.

(7) None of these objects show evidence of unusual age, and none bear traces of the wear and tear that would come from transportation in Tertiary torrents. These striking facts relating to the condition of the human remains confirm and enforce the impressions received from a study of the geological and biological history of the region.

(8) The case against antiquity is strengthened again by a study of the recent history of California. All the phenomena relied upon to prove antiquity can be accounted for without assuming a Tertiary man. Indian tribes have occupied the region for centuries. They buried their dead in pits, caves, and deep ravines where the remains were readily covered by accumulations of debris or of calcareous matter deposited by water. As soon as mining operations began the region became noted as a "place of skulls" (Calaveras).

(9) Coupled with the above is the fact that no other country in the world has been so extensively and profoundly dug over as this same Auriferous Gravel region. The miners worked out the ossuaries and, at the same time, undermined the village sites, and thousands of the native implements and utensils were introduced into the mines and became intermingled with the gravels. Implements and utensils may alse have been introduced into the deep mines by their owners who were helpers in the mining work.

(10) When these objects began to be observed by the miners, individuals interested in relics commenced to make collections, but neither miners nor collectors understood the need of discrim. ination, the fact that the objects came from the mines being satisfactory evidence to them that they belonged originally in the gravels.

(II) Again, it is possible that deception was often practiced. 
A mining camp is the natural home of practical joking, and the notion that finds of human relics in the gravels tended to excite heated discussion would spread quickly from camp to camp until the whole region would be affected.

(12) The testimony furnished is greatly weakened by the facts (I) that the finds on which it was based were made almost wholly by inexpert observers, and (2) that all were recorded at second hand. Affidavits cannot redeem it. Nothing short of expert testimony, amply verified and vigorously stated, will convince the critical mind that a Tertiary race of men using symmetrically shaped and beautiful implements, wearing necklaces of wampum and polished beads of marble or travertine bored accurately with revolving drills, fishing with nets weighted with neatly grooved stone sinkers, and having a religious system so highly developed that at least two forms of ceremonial stones had been specialized, occupied the American continent long enough to develop this marked degree of culture without leaving numerous and distinctive traces of its existence. 